GLOBAL JOURNAL OF GEOLOGICAL SCIENCES VOL. 18, 2020: 63-73

COPYRIGHT@ BACHUDO SCIENCE CO. LTD PRINTED IN NIGERIA ISSN 1596-6798

63

www.globaljournalseries.com, Email: info@globaljournalseries.com

\title{
GRANULOMETRY, HEAVY MINERAL AND GEOCHEMICAL STUDIES OF STREAM SEDIMENTS AROUND BULA, DASS DISTRICT, NORTHEAST NIGERIA
}

\author{
C. I. ADAMU, E. E. OKON*, AND D. O, INYANG
}

(Received 24January 2019; Revision Accepted 13June 2019)

\begin{abstract}
Active stream sediments generally consist of broken-down fragments of pre-existing rocks by the action of river (stream) flow. This makes them target materials for routine geochemical surveys and provenance analysis. Fifteen (15) stream sediment samples were collected in some parts of Bula and its environs, northeastern Nigeria, in order to determine their textural characteristics, heavy mineral and elemental composition. The sediments were subjected to granulometric, heavy mineral and elemental analyses. The result of granulometric analysis show that the stream sediments are poorly to moderately well sorted, very platykurtic to leptokurtic, fine to medium grained and positively skewed. Zircon, rutile and tourmaline are the dominant heavy mineral species occurring in the sediments. The computed Zircon-Tourmaline-Rutile (ZTR) index values for the samples range from 59.18 - 83.53, indicating mineralogical maturity. The geochemical data of the stream sediment samples show that the mean contents of the trace elements [ $\mathrm{Ti}(0.73 \pm 0.74 \%), \mathrm{Fe}(0.39 \pm 0.19 \%), \mathrm{Cr}(816 \pm 639 \mathrm{ppm}), \mathrm{Ni}(258 \pm 108 \mathrm{ppm}), \mathrm{Pb}(48 \pm 12.37 \mathrm{ppm})$ and $\mathrm{Zn}$ $(502 \pm 126 \mathrm{ppm})]$ were higher than their respective average crustal values except for Fe. Computed threshold values indicate possible mineralization containing $\mathrm{Fe}$ and $\mathrm{Ti}$. The elements have variable spatial distribution. The study shows that the trace elements composition of the stream sediments is majorly lithogenic. Because mineralization in rocks and sediments are often characterized by considerable variation in their trace elements contents, the metal concentrations in these sediments are large enough for IImenite and Rutile mineralization to be suspected within the study area.
\end{abstract}

\section{INTRODUCTION}

Nigeria is endowed with many base metal mineralization that altogether form the metallogenic provinces of the country (Elueze and Olade, 1985). The quest for solid mineral development in the country has resulted in various methods now being applied in the exploration of mineral resources in Nigeria. Stream sediment survey is employed almost exclusively for reconnaissance studies in drainage basins. By determining the chemical composition of the stream sediments and/or the heavy minerals separated from them, it is possible to recognize geochemical or mineralogical anomalies within a catchment area and trace them to their sources (Levinson, 1974). Active stream sediments represent the fine to medium-grain solid (clayey-silty-sandy) material, which consists of fragments that are mostly derived from the erosion of weathered rocks and soil by stream or river water. Depending on their particle size and stream water velocity, sediments are transported in solution, in suspension or as bed load. Thus, stream sediments represent the best composite of materials from the catchment area of the stream drainage network (Ranasinghe et al., 2009) and are commonly used as an exploration tool for regional geochemical surveys (Cohen et al., 1999; Cannon et al., 2004) as well as for provenance studies (Mange and Wright, 2007; Okon and Essien 2015).

Stream sediments surveys are based on the concept that fluvial and chemical processes carry metals and minerals from within a drainage catchment (watershed) to a site of mineral (and metal) accumulation commonly termed an anomaly. The characteristics (mineralogy, particle-size and geochemistry) of stream sediments commonly reflect the composition of source rocks, their weathering products, hydrological features, winnowing and sorting, climate and anthropogenic activities, as well as several other, possibly less important, factors of the basin (Grunsky et al., 2009; Ranasinghe et al., 2009; Singh, 2010; Adamu et al., 2015).

The anomalous metal content in stream sediments

C. I. Adamu, Department of Geology, University of Calabar, Calabar, Nigeria.

E. E. Okon, Department of Geology, University of Calabar, Calabar, Nigeria.

D. O, Inyang, Department of Geology University of Calabar, Calabar, Nigeria. 
decreases downstream through dilution from nonmineralized material thereby forming a dispersion train. Catching the dispersion train (ie correctly identifying just what is anomalous) is a key to detecting a mineralized source (Levinson, 1974). The study of the size fractions in a stream sediment sample provides the best opportunity for recognizing different geological processes that can have a strong influence on how the geochemistry of an area may be interpreted in terms of sediment provenance, transport history and depositional conditions (Grunsky, et al., 2009). The particle size distribution, the composition and assemblages of heavy minerals in sediments are used to predict their dispersal patterns, sediment sources (provenance) as well as the environment of deposition (Pettijohn, 1975; Basu, 2003). Placer deposit results when flowing water, particularly streams and rivers, lead to an accumulation of mechanically segregated minerals. Selley (1976) described their formation as a result of winnowing activities of current to concentrate a lag of denser materials (grains) of economic importance. The erosion of weathered rocks and minerals, result in the concentration of the more resistant and higher specific gravity (density) minerals (2.89). This research was carried out with the aim of determining the nature, origin and transportation history of the stream sediments around Bula, NE Nigeria. The study also attempted to delineate possible mineralized areas so that attention could be focused on localised areas with high economic interest.

\section{STUDY AREA DESCRIPTION}

The study area is part of the Northeastern Nigerian basement complex bounded by latitudes $9^{\circ} 58^{\prime}$ to $10^{\circ}$ $02^{\prime} \mathrm{N}$ and longitudes $9^{\circ} 30^{\prime}$ to $9^{\circ} 38^{\prime} \mathrm{E}$ (Fig. 1). The study area is accessible through the Dass - Doit, Dass Dajim and Dass - Bula major roads. Other sites were visited through minor roads and footpaths. The area is undulating and hilly with elevations up to $400-500 \mathrm{~m}$ above mean sea level. The Dass pluton located in the northwest of the study area rises up to $800 \mathrm{~m}$ above sea level and constitutes a prominent high in the area. A few isolated hills of about $500-700 \mathrm{~m}$ occur in the extreme southeastern part of the study area. River Kamel is the major drainage with several tributaries whose source is taken from the hills at Dass and towards the extreme southeast. The pattern of flow is dendritic. The area falls under semi-arid tropical climate with two distinct seasons (wet and dry seasons). At least seven months of the year are dry, and rain, confined to a short season, averages $200-300 \mathrm{~mm}$ mostly in May to September. Summers are hot with mean temperatures varying from 33 to $36^{\circ} \mathrm{C}$. Monthly mean minimum temperatures fall in the range of 18 to $21^{\circ} \mathrm{C}$. The winter period is characterized by the harmattan, a dry and dusty wind that blows across the Sahara Desert. The vegetation is Sahel savannah type with little continuous cover and a dangerous tendency to merge into desert because of overstocking and over farming. The study area is grassland with scattered areas of woodland and shrubland.

Geologically, the study area falls within the region dominated by crystalline rocks including gneisses, migmatites and metasediments of Precambrian age. The major rock units of the area include granite gneiss, migmatitic gneiss and diorite. Others include granites and pegmatites (Haruna et al., 2008).

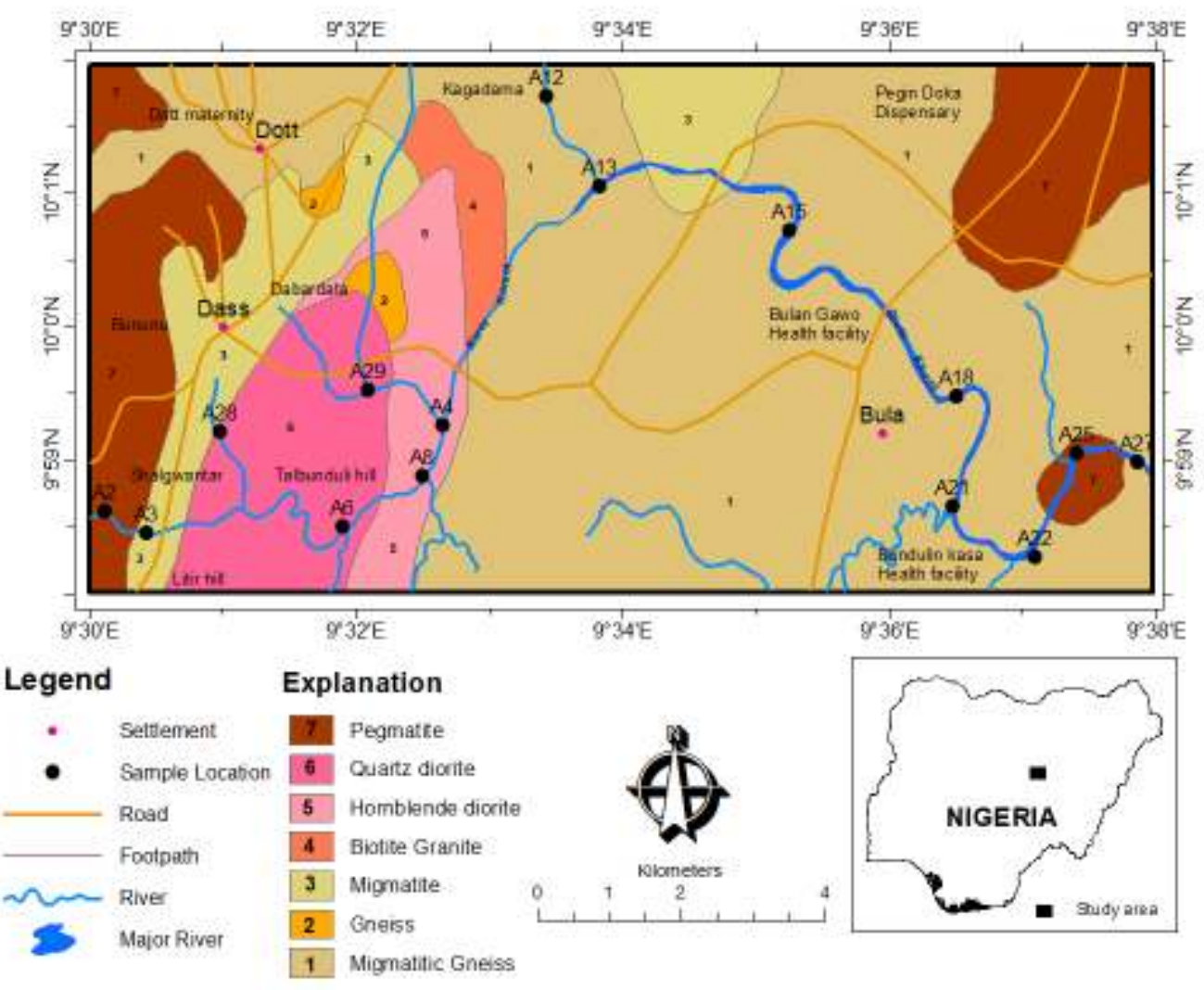


Migmatite gneiss is the major rock unit and mostly intruded by granitoids of the Older Granite suite (granodiorite, diorites) during the Pan-African orogeny $(600 \pm 150$ My). Rahaman (1976) recognised five petrological units within the Basement Complex of Nigeria, namely: (i) migmatite-gneiss complex; (ii) slightly migmatised paraschists; (iii) charnokite rocks, meta-gabbros and diorites; (iv) Older Granites and (v) un-metamophosed dolerite dykes and hypabyssal intrusive. Available age data (Ekwueme, 2005) indicate that Nigerian Basement Complex is mainly of Proterozoic age and has been involved in at least two orogenic events. During the first event, the Eburnean orogeny $(1850 \pm 250 \mathrm{Ma})$ pre-existing ancient sediments and volcanic were subjected to widespread migmatization and granitization. There was also local mobilization and intrusion of granites. Rocks formed during this ancient granitic cycle are represented by gneisses, quartzites, schists and amphibolites. These rocks constitute the bulk of the migmatite-gneiss complex. The second orogeny, known as the PanAfrican Orogeny $(600 \pm 150 \mathrm{Ma})$ is characterised by local migmatization, mobilization and intrusion of granites, known as Older Granites.

\section{MATERIALS AND METHODS}

The research was carried out in two broad segments: field study and laboratory analysis. Detailed field work was carried out during which close observation was made on all outcrops, noting the various rock types, their structural attributes and the degree of weathering. The nature and process of streams and their sediments was noted as well as the land use pattern. A total of fifteen
(15) grab samples were collected from active stream channels. The sediment samples were collected from the banks and mid-section of the stream channels. Both sub-samples at each location were homogenized(thoroughly mixed together) to obtain a composite sample. There sediment samples were subjected to laboratory procedures involving cone and quartering. Quarters from the left and right were recombined to reduce bias and reduce the sample into two sets; these were selected for further analyses. One set of the samples was subjected to sedimentological (sieve analysis and heavy mineral analysis) analysis and the other set to geochemical (elemental) analysis. The stream sediment samples were air dried, disaggregated and subjected to grain size analyses out of which the fine $(75 \mu \mathrm{m})$ sediments were selected for heavy mineral analysis. $500 \mathrm{grams}$ of sediment samples were subjected to sieve analysis using a mechanical sieve shaker. The sediments were shaken for 20 minutes and the weight retained in the sieve stack were measured and used for further computations. The sieve sizes used for this operation were as follows; $1.00 \mathrm{~m}, 850 \mu \mathrm{m}, 600 \mu \mathrm{m}$, $425 \mu \mathrm{m}, 300 \mu \mathrm{m}, 212 \mu \mathrm{m}, 180 \mu \mathrm{m}, 150 \mu \mathrm{m}$ and $90 \mu \mathrm{m}$. Each cumulative percentage was obtained as a percentage of the cumulative corrected weight to the total corrected weight. The grain size of the $5^{\text {th }}, 16^{\text {th }}$, $25^{\text {th }}, 50^{\text {th }}, 75^{\text {th }}, 84^{\text {th }}$ and $95^{\text {th }}$ percentiles were obtained from each cumulative curve drawn. These were used to calculate statistical parameters such as the Graphic Mean (M), Standard Deviation (sorting) (SD), Graphic Kurtosis (K) and Graphic Skewness (SK) based on Folk and Ward (1957) as follows:

Graphic mean $(M)=\frac{\phi_{16}+\phi_{50}+\phi_{84}}{3}$

Standard deviation (sorting, $\sigma)=\left[\frac{\phi_{84}-\phi_{16}}{4}\right]+\left[\frac{\phi_{95}-\phi_{5}}{6.6}\right]$

Kurtosis $\left(K_{G}\right)=\frac{\phi_{95}-\phi_{5}}{2.44\left(\phi_{75}-\phi_{25}\right)}$

Graphic Skewness $\left(S_{k}\right)=\left[\frac{\phi_{84}+\phi_{16}-2\left(\phi_{50}\right)}{2\left(\phi_{84}-\phi_{16}\right)}\right]+\left[\frac{\phi_{95}+\phi_{5}-2\left(\phi_{50}\right)}{2\left(\phi_{95}-\phi_{5}\right)}\right]$

Where:

$\phi \mathrm{n}$ is the nth percentile of the size distribution taken from the cumulative frequency curve;

$\phi$ is the weight of sediment per size class as a percentage of the total sample weight;

Heavy mineral separation was carried out on the $75 \mu \mathrm{m}$ fraction according to the methods outlined by Carver (1971), where bromo form $(2.96 \mathrm{~g} / \mathrm{cc})$, clerici solution $(4.3 \mathrm{~g} / \mathrm{cc}$ ) and magnets (Fig 2) were used to achieve the separation. The method was based on gravity settling technique whereby upon immersion, the heavies (> 2.96 $\mathrm{g} / \mathrm{cc}$ ) since and the light fractions float. These were then collected in a filter paper using a separating funnel. After drying the heavy concentrates were then immersed into cleric solution $(>4.3 \mathrm{~g} / \mathrm{cc}$ ) to further separate heavier minerals. During the separation process, the strongly magnetic minerals adhered to magnets covered with polyethene, the weakly magnetic minerals only attached to the magnet with direct contact while the non-magnetic minerals were not attracted even with direct contact.A bar magnet was used to separate grains that had magnetic affinities. The summary of the separation procedure is given in Figure 2. The separated minerals and the gangue were then mounted on glass slides and their diagnostic characteristics were examined using petrological microscope.

For the purpose of chemical analysis, $0.5 \mathrm{~g}$ of each sample was digested using $10 \mathrm{ml}$ of $16 \mathrm{M} \mathrm{HNO}_{3}$ mixed with $12 \mathrm{M}$ of $\mathrm{HCl}(3: 2$, vol: vol). The samples were refluxed at $75^{\circ} \mathrm{C}$ and then evaporated to dryness in about 24 hours. Leaching was carried out using $5 \mathrm{ml}$ of 
$6 \mathrm{M} \mathrm{HCl}$. The resulting sample solutions was analysed for $\mathrm{Cr}, \mathrm{Fe}, \mathrm{Ni}, \mathrm{Pb}, \mathrm{Ti}$ and $\mathrm{Zn}$ using Bulk Scientific Atomic Adsorption Spectrometer (AAS-VGB system) model Perkin Elmer AA 700 AAS equipment at the Nigerian Mining Corporation (NMC), Jos, Nigeria. The AAS was equipped with deuterium background corrector. The analytical precisions for the analysed elements at $95 \%$ confidence levels were $\mathrm{Pb}(94 \%)$, Ni (92\%), $\mathrm{Cr}(92 \%)$, Fe (90\%), Zn (84\%), Ti (78\%).
The data obtained were analysed using the statistical package for social sciences (SPSS -Version 20) for mean, range, standard deviation (SD) and correlation analysis. Also, the Zircon-Tourmaline-Rutile (ZTR) index was calculated using the percentage of the combined zircon, tourmaline and rutile grains for each sample according to the formula below.

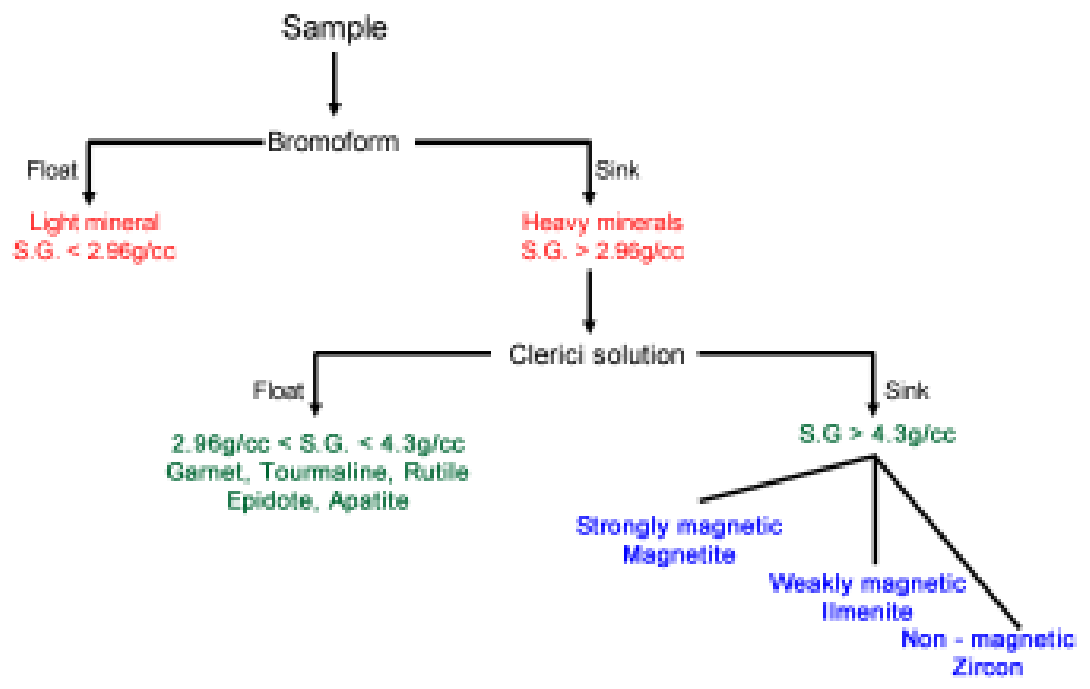

FIG 2. Flow chart showing the heavy mineral separation scheme used in the study

ZTR index $=\frac{\text { Zircon }+ \text { Tourmaline }+ \text { Rutile }}{T n} * 100 \%$

Where $\mathrm{Tn}=$ Total number of non-opaque heavy minerals

The calculated index is expressed in percentage to ascertain the mineralogical maturity of the sediment. According to Hubert (1962), ZTR <75\% implies immature to sub mature sediments and ZTR $>75 \%$ indicates mineralogical matured sediments. Apart from the ZTR index, various frequency percentage plots of both pie and bar charts were made for each sample location and their statistical parameters (graphic - mean, standard deviation, skewness and kurtosis) were extracted from them.

\section{RESULTS AND DISCUSSION}

The results of the sieve analysis of the stream sediments samples are presented in Table 1. The different statistical parameters derived from the graph plots of cumulative weight percentage against phi $(\phi)$ of the different locations are presented on Table 2. Only four statistical parameters are used for this work: mean, inclusive standard deviation (sorting), inclusive graphic skewness (SK) and graphic kurtosis $\left(\mathrm{K}_{\mathrm{G}}\right.$

Table 1. Grain Size Analysis results of the stream sediment samples

\begin{tabular}{|l|llllllllll|}
\hline Sample ID & $\mathbf{1 . 0} \mathbf{m m}$ & $\mathbf{8 5 0} \boldsymbol{\mu m}$ & $\mathbf{6 0 0} \boldsymbol{\mu m}$ & $\mathbf{4 2 5} \boldsymbol{\mu m}$ & $\mathbf{3 0 0} \boldsymbol{\mu m}$ & $\mathbf{2 5 0} \boldsymbol{\mu m}$ & $\mathbf{1 8 0} \boldsymbol{\mu m}$ & $\mathbf{1 5 0} \boldsymbol{\mu m}$ & $\mathbf{9 0} \boldsymbol{\mu m}$ & Pan \\
\hline A2 & 65 & 40 & 50 & 55 & 50 & 60 & 90 & 35 & 30 & 25 \\
A3 & 60 & 65 & 70 & 65 & 80 & 85 & 45 & 15 & 10 & 5 \\
A4 & 15 & 30 & 40 & 50 & 100 & 150 & 70 & 35 & 25 & 15 \\
A6 & 30 & 35 & 50 & 40 & 75 & 100 & 70 & 40 & 40 & 20 \\
A8 & 20 & 25 & 30 & 35 & 60 & 135 & 100 & 50 & 30 & 15 \\
A12 & 30 & 20 & 75 & 20 & 75 & 135 & 120 & 8 & 5 & 12 \\
A13 & 6 & 8 & 22 & 66 & 144 & 72 & 68 & 73 & 34 & 7 \\
A15 & 14 & 18 & 24 & 112 & 123 & 98 & 62 & 19 & 16 & 14 \\
A18 & 20 & 15 & 20 & 50 & 100 & 125 & 110 & 35 & 20 & 5 \\
A19 & 18 & 22 & 20 & 36 & 94 & 106 & 72 & 76 & 30 & 20 \\
A22 & 13 & 17 & 36 & 56 & 68 & 97 & 123 & 54 & 26 & 10 \\
A25 & 20 & 25 & 60 & 76 & 102 & 98 & 46 & 33 & 32 & 8 \\
A27 & 45 & 50 & 60 & 100 & 55 & 45 & 45 & 50 & 40 & 10 \\
A28 & 35 & 46 & 50 & 60 & 60 & 90 & 100 & 28 & 19 & 12 \\
A29 & 25 & 25 & 35 & 45 & 45 & 80 & 110 & 70 & 45 & 20 \\
\hline
\end{tabular}


Table 2. Statistical parameters derived from textural analysis

\begin{tabular}{|l|l|l|l|l|}
\hline Sample ID & Mean & Sorting & Kurtosis & Skewness \\
\hline A2 & 1.07 & 0.66 & 0.82 & 0.40 \\
A3 & 1.03 & 0.90 & 1.93 & -0.09 \\
A6 & 1.61 & 1.08 & 2.12 & -1.30 \\
A8 & 1.80 & 0.93 & 1.18 & -1.05 \\
A9 & 1.64 & 0.89 & 0.97 & -0.90 \\
A12 & 1.14 & 0.97 & 1.99 & -0.34 \\
A13 & 1.84 & 0.73 & 1.09 & 0.15 \\
A15 & 1.57 & 0.75 & 0.99 & -0.12 \\
A18 & 1.77 & 0.74 & 0.91 & -1.30 \\
A19 & 1.84 & 0.90 & 1.42 & -0.65 \\
A22 & 1.78 & 0.83 & 1.21 & -1.18 \\
A25 & 1.52 & 0.91 & 1.28 & -0.31 \\
A27 & 1.36 & 1.16 & 2.71 & 1.03 \\
A28 & 1.46 & 1.01 & 1.87 & -2.11 \\
A29 & 2.32 & 0.62 & 0.65 & -2.85 \\
\hline
\end{tabular}

\section{TRANSPORTATION HISTORY}

The mean values of graphic statistical parameters were used for textural classification of the sediments, since it describes the average grain size of the sediments. The graphic mean values obtained range from $1.02-2.32$ (fine - medium grain). The lowest mean value belongs to sample A3, while the peak value of 2.32 is associated with sample A29. According to Folk and Ward (1957), the mean values that fall within the range from 1.00-2.00 are described as medium grained. From this study, it was observed that 14 samples (about 93.33\%) fell within this group. The sample (A29) with a mean value 2.32 is described as containing fine grained sediments. Therefore, two main sediment size types which vary from medium to fine grain are present. The medium grained sediments observed were associated with high energy conditions in which smaller grains were washed away leaving the medium, sandy grains that were relatively heavy and were deposited by gravity as the water current was reduced. Such sediments are suggested to be within the middle course of a river regime (Ikhane, et al., 2013). This implies that majority of the samples were collected within the middle channels. On the contrary, the fine-grained sediments of the single sample were associated with a location further down the river channel at a relatively lower energy of transportation (Fig. 1).

Moreover, the mean values of the samples generally increased towards the source of streams. Deviations from this general trend were probably due to influence of tributaries and the decrease in velocity (energy) encountered at stream bends. Hence, a form of lateral gradation or down grading phenomenon is obtained, whereby, sample from locations A2, A3, A12 and A15 were weathered, transported and deposited at the upper course of the river have larger grain sizes compared to locations downstream.

Another important statistical parameter utilized for the deduction of the transport history is inclusive standard deviation (sorting). The sorting measures the scatter around the mean and the greater the scatter, the higher the standard deviation and the poorer the sorting. The statistical calculation indicated sorting values that ranged from 0.62 - 1.16. The lowest value (0.62) corresponds to location A29 while the highest (sorting) value (1.16) belongs to location A27. The classification class of $0.5-0.7$ defined as moderately well sorted was only found in 2 (13.33\%) locations A2 and A29; 0.71 1.0 defined as moderately sorted encompasses 10 (66.67\%) sample locations A3, A8, A9, A12, A13, A15, A18, A19, A22; while values ranging from 1.0-2.0 defined as poorly sorted was associated with $3(20.00 \%)$ sample locations A6, A27 and A28. The spread of sorting values is a reflection of distance of transportation, energy and environment of deposition as described for "mean". Therefore, the poorly sorted sediments of location A6 that have not been transported far away from their source indicates high energy of transportation which did not permit hydraulic sorting and was probably associated with flash flood of water volume. On the other hand, relatively high rate of sedimentation was suggested to be responsible for the poor sorting at locations A27 and A28. On the other hand, the moderately sorted sediments indicate that they have been transported relatively further away from their source. The relatively lower energy of transportation at regular intervals therefore permitted fair hydraulic sorting at the lower course of the streams. The 2 locations that are moderately well sorted have most probably been transported very far from source at regular low energy of transportation and relatively low sedimentation rate.

The Inclusive graphic skewness (SK) determines or measures symmetry in the scatter of a distribution as well as the degree of lop-sidedness of a curve. The skewness (SK) values range from $-2.85-1.03$. These values show that the data are negatively skewed except for three (20\%) locations (A2, A13, and A27). This implies that the sediments are symmetrical to strongly coarsely skewed. A classification group of $0.1-0.3$ 
defines finely skewed sediments such as location $A 12$; while 0.3-1.0 defines severely finely skewed sediments such as may be found in A2 and A27. The fine skewed nature of the sediments exhibits sediments input from various sources of tributaries whereas the severely finely skewed nature implies a low velocity than normal. The graphic kurtosis is the peakedness of the distribution and measures the ratio between the sorting of the tails and central portion of the curve. If the tails are better sorted than the central portion, then it is termed as platykurtic, whereas leptokurtic, if the central portion is better sorted. The sorting kurtosis of the sediments shows that they vary from very platykurtic $(<0.65)$ to leptokurtic $(1.50-3.00)$.

\section{SOURCE AREA OF THE SEDIMENTS}

The result of heavy mineral analysis is presented in Table 3. Table 3 also contains computed values of ZTR index. The results show that the heavy mineral suite consist of opaque and non-opaque minerals.

Table 3. Results of heavy mineral analysis of the stream sediment samples

\begin{tabular}{|c|c|c|c|c|c|c|c|c|c|c|c|c|}
\hline \multirow[b]{2}{*}{$\begin{array}{l}\text { Sample } \\
\text { ID }\end{array}$} & \multicolumn{10}{|c|}{ Heavy Minerals } & \multirow[b]{2}{*}{ 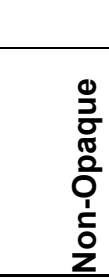 } & \multirow[b]{2}{*}{ 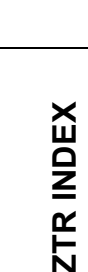 } \\
\hline & 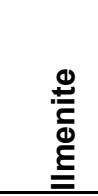 & 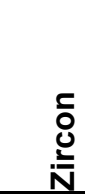 & 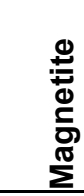 & 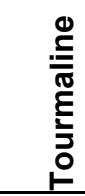 & 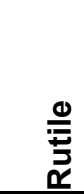 & $\begin{array}{l}\stackrel{0}{ \pm} \\
\frac{\pi}{0} \\
\frac{0}{5} \\
\frac{\pi}{\pi} \\
0\end{array}$ & 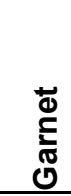 & 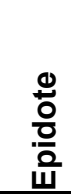 & 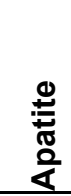 & 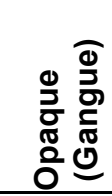 & & \\
\hline A2 & 3.0 & 10.0 & 3.0 & 6.0 & 8.0 & 4.0 & 1.0 & 2.0 & 4.0 & 65.0 & 35.0 & 68.57 \\
\hline A3 & 3.0 & 13.0 & 2.0 & 3.0 & 11.0 & 5.0 & 2.0 & 1.0 & 2.0 & 63.0 & 37.0 & 72.97 \\
\hline A6 & 3.0 & 15.0 & 8.0 & 7.0 & 6.0 & 5.0 & 1.0 & 1.0 & 1.0 & 64.0 & 36.0 & 77.78 \\
\hline A8 & 2.8 & 19.0 & 1.0 & 2.0 & 4.0 & 10.0 & 4.0 & 0.0 & 2.0 & 86.0 & 41.0 & 60.98 \\
\hline A9 & 4.0 & 16.0 & 2.0 & 5.0 & 6.0 & 8.0 & 2.0 & 1.0 & 1.0 & 90.0 & 39.0 & 69.23 \\
\hline A12 & 3.0 & 24.0 & 5.0 & 5.0 & 8.0 & 7.0 & 1.0 & 2.0 & 3.0 & 84.0 & 50.0 & 74.00 \\
\hline A13 & 4.0 & 15.0 & 7.0 & 6.0 & 7.0 & 6.0 & 3.0 & 0.0 & 2.0 & 92.0 & 39.0 & 71.79 \\
\hline A15 & 4.0 & 23.0 & 6.0 & 44.0 & 4.0 & 9.0 & 2.0 & 0.0 & 3.0 & 74.0 & 85.0 & 83.53 \\
\hline A18 & 3.0 & 22.0 & 4.0 & 6.0 & 6.0 & 5.0 & 1.0 & 0.0 & 1.0 & 80.0 & 41.0 & 82.93 \\
\hline A19 & 3.0 & 20.0 & 2.0 & 4.6 & 8.0 & 6.0 & 1.0 & 1.0 & 2.0 & 83.0 & 42.6 & 76.53 \\
\hline A22 & 4.0 & 24.0 & 2.0 & 5.0 & 8.0 & 10.0 & 3.0 & 1.0 & 2.0 & 78.0 & 53.0 & 69.81 \\
\hline A25 & 2.0 & 26.0 & 2.0 & 3.0 & 10.0 & 4.0 & 2.0 & 1.0 & 3.0 & 88.0 & 49.0 & 79.59 \\
\hline A27 & 3.0 & 27.0 & 3.0 & 3.8 & 6.0 & 9.0 & 2.0 & 2.0 & 1.0 & 70.0 & 50.8 & 72.44 \\
\hline A28 & 6.0 & 11.0 & 6.0 & 9.6 & 14.0 & 12.0 & 3.0 & 1.0 & 4.0 & 68.0 & 54.6 & 63.37 \\
\hline A29 & 3.0 & 10.0 & 6.0 & 7.0 & 12.0 & 12.0 & 2.0 & 2.0 & 4.0 & 69.0 & 49.0 & 59.18 \\
\hline Min & 2.0 & 10.0 & 1.0 & 2.0 & 4.0 & 4.0 & 1.0 & 0.0 & 1.0 & 63.0 & 35.0 & 59.2 \\
\hline Max & 6.0 & 27.0 & 8.0 & 44.0 & 14.0 & 12.0 & 4.0 & 2.0 & 4.0 & 92.0 & 85.0 & 83.5 \\
\hline Mean & 3.4 & 18.3 & 3.9 & 7.8 & 7.8 & 7.4 & 2.0 & 1.0 & 2.3 & 76.9 & 46.8 & 72.2 \\
\hline SD & 0.9 & 5.9 & 2.2 & 10.2 & 2.8 & 2.7 & 0.9 & 0.7 & 1.1 & 10.0 & 12.4 & 7.3 \\
\hline CV (\%) & 26.5 & 32.2 & 56.4 & 131 & 40 & 36.5 & 45 & 70 & 48 & - & - & - \\
\hline
\end{tabular}

$\mathrm{CV}=$ Coefficient of variation

The opaque mineral constituents make up more that 60 $\%$ of the mineral distribution across the sample locations. The spatial distribution of the heavy minerals reveals the highest occurrences in samples obtained in River Kamel (A-4, 6, 8, 13, 15, 18, 22, 25, 27) when compared to the samples obtained from tributary streams $(A-2,3,12,28,29)$. This may be attributed to the fact that River Kamel serves as site of mineral accumulation from the tributaries. However, samples collected close to the source of the tributaries $(A-28,29)$ also contained relatively high level of some heavy minerals. Suresh Ghandi and Raja (2014) opined that an increase in heavy mineral content downstream is often attributed to the decrease in gradient and velocity thereby leading to accumulation.

As shown, the stream sediments show enrichment of heavy minerals in the finer sediments (Table 3 ). This is consistent with earlier views that the fines increase away from the source. Such an enrichment in the finer grade is mainly due to selective removal of light minerals leaving behind coarser and high-density minerals (Frihy and Komar, 1991) for the different fractions. Our findings are also consistent with the finding of Hanamgond and Nayak (2011).Local deviation from the general trend may reflect mineral concentrations in convex sides of streams marked by low flow and high sedimentation (point bars). The implication of the increasing occurrence of heavy minerals downstream is that there is the probability of higher accumulation in the river which River Kamel drains into. Hence the need to identify and thoroughly investigate the river for possible occurrence of placer deposits. Photomicrographs showing some selected heavy minerals is presented in Figure 3. 


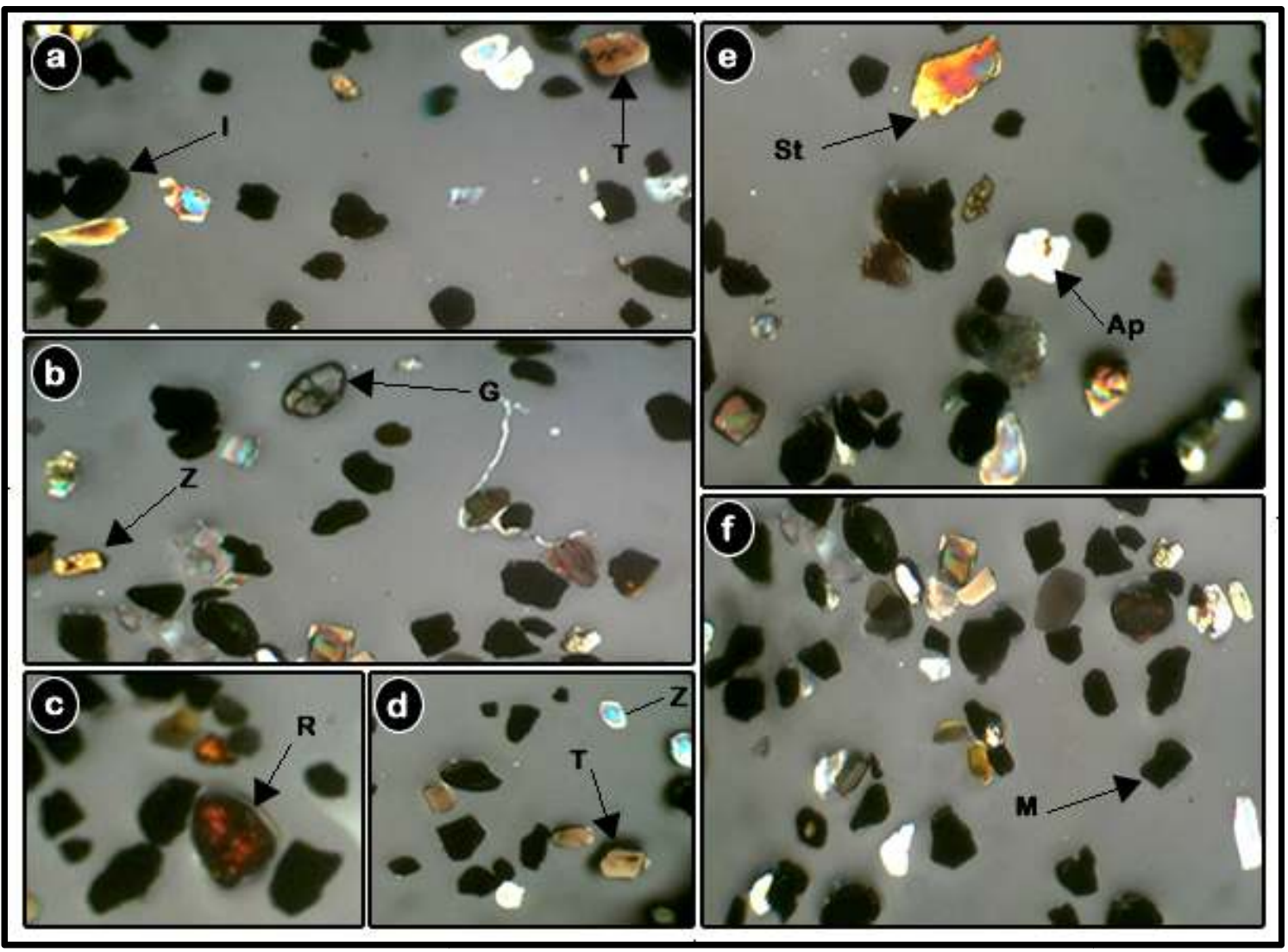

FIG 3. Photomicrographs showing distribution of heavy mineral grains (a) Sample A15 (b) Sample A25 (c) Sample A13 (d) Sample A6 (e) Sample A8 and (f) Sample A28 [T - tourmaline; St - staurolite; I - ilmenite; M - magnetite; R rutile; Z - zircon; G - garnet; Ap - apatite]

The Pie chart (Fig. 4) shows the relative composition of the heavy minerals across the locations. Zircon is most abundant $(33.95 \%)$ followed by Rutile $(14.47 \%)$ and Tourmaline $(14.47 \%)$, Staurolite $(13.73 \%)$, Magnetite (7.24\%), Ilmenite (6.31\%), Apatite (4.27\%), Garnet $(4.27 \%)$ and Epidote $(1.86 \%)$. The order of distribution is almost repeated at all the locations except at A28 and A29 where Rutile has the highest occurrence. The occurrence of the heavy minerals varies considerably with location. Tourmaline is the most variable heavy mineral with coefficient of variation (CV) of $131 \%$ and ilmenite is the least variable with a $C V=26.50 \%$.

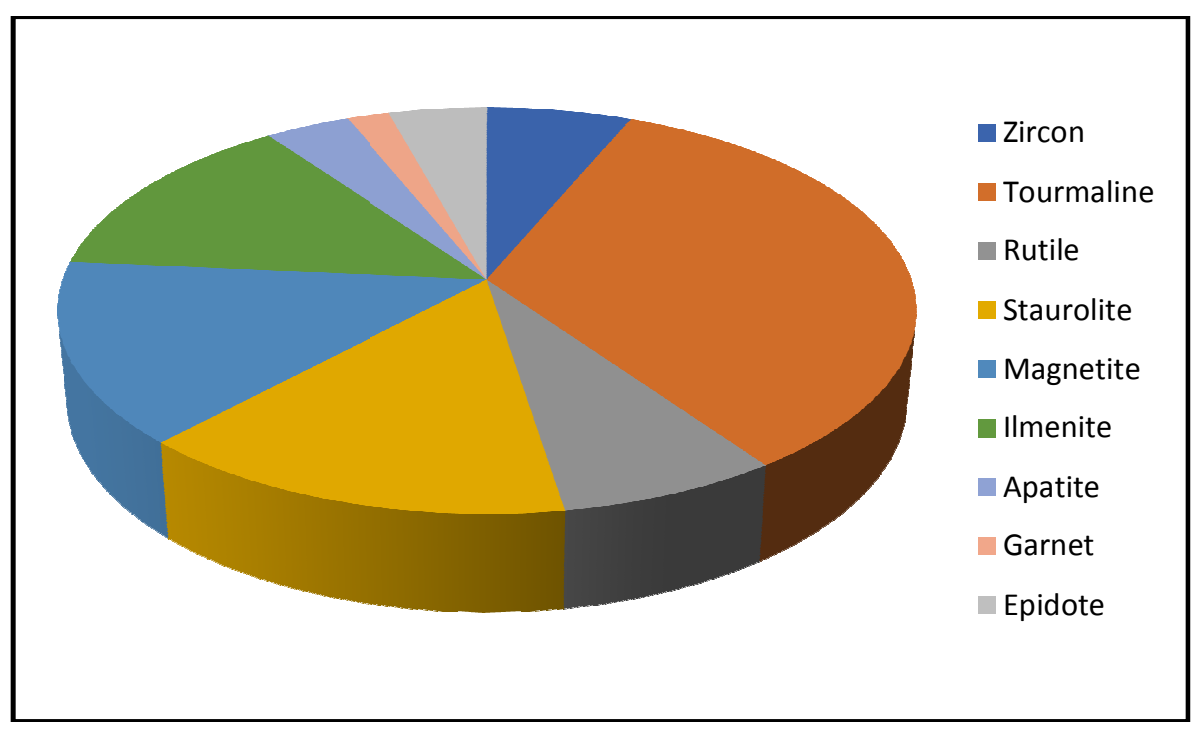

FIG4. Pie chart showina the relative concentration of the heavv minerals 
The spatial variation of the heavy minerals is most probably a function of the source rock, transport distance and hydraulic condition of the channel of deposition (Hanamgond and Nayak, 2011). The ZTR Index calculated from the result of heavy mineral analysis for the stream sediments samples varies from $59.18-83.53 \%$. All of the sample locations have ZTR index values of $>50 \%$. The high ZTR indices suggest that almost all the locations contain mineralogical immature sediments (See Table 3).

An attempt has been made to establish the parent rocks or provenance of the heavy minerals based on known geology of the area as well as the occurrence and associations of accessory minerals. The highest levels of the heavy minerals were associated with specific lithogenic unit over which the streams are draining. The minerals like garnet, staurolite, tourmaline and epidote are highest on and may be assigned to the contribution of different high-grade metamorphic rocks (migmatites and gneisses). The opaque's (mainly of ilmenite and magnetite) were mainly from basic igneous rocks (biotite granites and hornblende diorite), zircon, apatite and rutile might have been derived from igneous rocks of acidic compositions (pegmatites) of the study area.

\section{GEOCHEMICAL COMPOSITION}

The results of the trace elements composition of the stream sediment samples are presented in Table 4. The trace elements are not uniformly distributed and may indicate multiple population or suggest different geochemical controls on trace elements distribution in the stream sediments. Six metals were analysed with $\mathrm{Ti}$ and $\mathrm{Fe}$ being the most abundant and range from 0.2 $0.71 \%$ and $0.1-0.84 \%$ respectively.

Table 4. Trace elements content of the stream sediments of the study area

\begin{tabular}{|l|lllllll|}
\hline $\begin{array}{l}\text { Sample } \\
\text { ID }\end{array}$ & $\begin{array}{l}\text { Bedrock } \\
\text { Lithology }\end{array}$ & $\begin{array}{l}\text { Ti } \\
(\%)\end{array}$ & $\begin{array}{l}\mathbf{F e} \\
(\%)\end{array}$ & $\begin{array}{l}\mathbf{C r} \\
(\mathbf{p p m})\end{array}$ & $\begin{array}{l}\mathbf{N i} \\
\text { (ppm) }\end{array}$ & $\begin{array}{l}\mathbf{P b} \\
\text { (ppm) }\end{array}$ & $\begin{array}{l}\text { Zn } \\
\text { (ppm) }\end{array}$ \\
\hline A2 & Pegmatite & 0.45 & 0.36 & 680 & 92 & 66 & 540 \\
A3 & Migmatite & 0.70 & 0.32 & 170 & 220 & 36 & 480 \\
A6 & Q. diorite & 0.71 & 0.81 & 312 & 130 & 40 & 440 \\
A8 & H. diorite & 0.20 & 0.10 & 2900 & 440 & 70 & 600 \\
A9 & H. diorite & 0.40 & 0.30 & 714 & 320 & 52 & 330 \\
A12 & M. gneiss & 0.50 & 0.46 & 380 & 200 & 60 & 370 \\
A13 & M. gneiss & 0.45 & 0.78 & 480 & 190 & 44 & 490 \\
A15 & M. gneiss & 0.20 & 0.50 & 860 & 300 & 32 & 560 \\
A18 & M. gneiss & 0.40 & 0.40 & 1220 & 280 & 46 & 720 \\
A19 & M. gneiss & 0.50 & 0.26 & 940 & 180 & 52 & 330 \\
A22 & M. gneiss & 0.30 & 0.24 & 560 & 380 & 36 & 486 \\
A25 & Pegmatite & 0.65 & 0.26 & 680 & 176 & 44 & 558 \\
A27 & M. gneiss & 0.38 & 0.38 & 640 & 330 & 68 & 626 \\
A28 & Migmatite & 2.70 & 0.44 & 790 & 430 & 58 & 680 \\
A29 & Q. diorite & 2.30 & 0.38 & 1100 & 360 & 60 & 700 \\
Min & - & 0.20 & 0.10 & 170 & 92 & 32 & 330 \\
Max & - & 2.70 & 0.81 & 2,900 & 440 & 70 & 720 \\
Mean & - & 0.72 & 0.39 & 816 & 258 & 48 & 502 \\
SD & - & 0.74 & 0.19 & 639.24 & 108.16 & 12.37 & 126.22 \\
CV (\%) & - & 103 & 48.7 & 78.3 & 41.9 & 25.7 & 25.1 \\
TV & - & 2.20 & 0.76 & 2095 & 474 & 73 & 754 \\
ACV & - & 0.57 & 3.50 & 100 & 75 & 22 & 70 \\
\hline
\end{tabular}

Q. diorite = Quartz diorite; M. gneiss = Migmatite gneiss; $\mathrm{H}$. diorite $=$ Hornblende diorite; $\mathrm{TV}=$ Threshold value, $\mathrm{CV}=$ Coefficient of variation, $\mathrm{ACV}=$ Average crustal abundance values (Levinson, 1974)

The coefficient of variations (CV \%) of the trace elements vary from a low $25.10(\mathrm{Zn})$ through $25.70(\mathrm{~Pb})$ $41.90(\mathrm{Ni}), 48.70(\mathrm{Fe}), 78.30(\mathrm{Cr})$ to $103(\mathrm{Ti}) . \quad$ This implies that $\mathrm{Ti}$ is the most variable trace element and $\mathrm{Zn}$ the least variable. The high variations in the concentration of trace elements in the stream sediments might imply that the rocks in Bula contain concentration of the trace elements that might constitute mineralization. This is consistent with the observation that mineralization in rocks is characterised by considerable variation in the trace element concentrations of stream sediments (Oboho et al., 2007).
The concentration of titanium $(\mathrm{Ti})$ ranges from 0.20 to $2.70 \%$ with a mean value of $0.72 \pm 0.74 \%$ and a threshold value of $2.20 \%$. The concentration of $\mathrm{Ti}$ in the stream sediment samples is higher than the average crustal abundance value (ACV) of $0.57 \%$ (Levison, 1974). The concentration of iron ( $\mathrm{Fe})$ in the stream sediments is lower than that of $\mathrm{Ti}$. The values of Fe vary from 0.10 to $0.81 \%$ with a mean and threshold value of $0.39 \pm 0.19 \%$ and $0.76 \%$ respectively. The concentration of $\mathrm{Fe}$ in the stream sediment samples is much lower than the average crustal abundance of $3.50 \%$. The mean concentration of chromium $(\mathrm{Cr})$ is $816 \pm 630 \mathrm{ppm}$. The highest concentration (2,900 ppm) recorded at location A8 was higher than the threshold value of 2,095 
ppm. Besides, the level of $\mathrm{Cr}$ in the stream sediments is more than 8 times its average crustal abundance of 100 ppm. The concentration of nickel $(\mathrm{Ni})$ in the stream sediments is lower than that of $\mathrm{Cr}$. The values of Ni vary from 92 to $440 \mathrm{ppm}$ with a mean and threshold value of $258 \pm 108$ and $474 \mathrm{ppm}$ respectively. The mean value of $\mathrm{Ni}$ is also higher than the average crustal abundance value of $75 \mathrm{ppm}$. Lead $(\mathrm{Pb})$ concentration ranges from 32 to $70 \mathrm{ppm}$ with a mean value of $48 \pm 12 \mathrm{ppm}$. The concentration of zinc varies from 330 to $720 \mathrm{pm}$ with a mean value of $502 \pm 126 \mathrm{ppm}$. All the values of $\mathrm{Pb}$ and $\mathrm{Zn}$ are below their respective threshold values of 73 and $754 \mathrm{ppm}$ but higher than their respective ACVs of 22 and $70 \mathrm{ppm}$.

The geochemical data obtained in the study demonstrate that the concentrations of the trace elements in the stream sediment samples are higher than their respective average crustal abundance values except for $\mathrm{Fe}$. This suggests the presence of accessory (heavy) minerals containing the trace elements within the rocks of the study area. However, the levels of the trace elements are generally below their threshold values (Table 4).

This implies that the levels of most trace elements in the stream sediments are lower than expected values for mineralisation. It may also be an indication of mechanical dispersion (Levinson, 1974). It was observed that the concentrations of $\mathrm{Ti}$ at two locations (A28 - 2.70\%; A29 - 2.30\%), Fe at two locations (A6 $0.81 \%$; $\mathrm{A} 13-0.78 \%$ ) and $\mathrm{Cr}$ at one location (A8) were higher than their respective threshold values of $2.20 \%$, $0.76 \%$ and $2095 \mathrm{ppm}$. The concentrations of these elements are relatively high and suggests the presence of placer deposit hosting minerals like ilmenite, magnetite, staurolite, tourmaline and rutile in these sediments (Peterson et al., 1986; Darby and Tsang 1987).Typically, these are directly sourced from the surrounding the host rocks from which these sediments are derived (Darby 1984; Basu and Molinaroli 1989).

\section{CORRELATION ANALYSIS}

In order to estimate the degree of interrelationship between trace elements in a manner not influenced by measurement units, the correlation coefficient ( $r$ ), which is the ratio of the covariance of two variances to the product of their standard deviation, is used (Davis, 1986; Joe, 2006). The correlation coefficient is a unit-less ratio number, which ranges between +1 and -1 , where +1 indicates a correlation of a perfect direct rectilinear relationship between two variables, and a correlation of 1 indicates that the variables have an inverse rectilinear relationship. Between the two extremes is a spectrum of less - than- perfect relationships including zero, which indicates complete lack of linear relationship. The Pearson correlation analysis was used in estimating the degree of relationship between variables in stream sediment samples. Table 5 shows the correlation matrix for the geochemical data of the stream sediment samples. These exist general weak correlations among the trace elements with $\mathrm{Ni}-\mathrm{Cr}(r=0.54)$ being the most strongly correlated while $\mathrm{Ti}-\mathrm{Cr}(\mathrm{r}=-0.06)$ is the least correlated (Table 5). The weak correlation may suggest the mixing of sediments derived from different lithologic units within the study area. Lithologic diversity tends to progressively mix sediments with a resultant heterogeneous sediment suite whose geochemical composition shows little relationship and is difficult to explain (Jimoh, et al., 2015). All the trace elements correlate negatively with $\mathrm{Fe}$ except $\mathrm{Ti}$ which shows a weak positive correlation. Similarly, $\mathrm{Ti}-\mathrm{Cr}$ shows weak negative correlation. This may imply that $\mathrm{Fe}$ is contributed from a source different from the other trace elements but a common source with Ti.

Table 5. Correlation coefficient matrix of the stream sediments geochemical data

\begin{tabular}{|l|llllll|}
\hline & $\mathrm{Ti}$ & $\mathrm{Fe}$ & $\mathrm{Cr}$ & $\mathrm{Ni}$ & $\mathrm{Pb}$ & $\mathrm{Zn}$ \\
\hline $\mathrm{Ti}$ & 1.00 & 0.10 & -0.06 & 0.34 & 0.21 & $\mathbf{0 . 4 5}$ \\
$\mathrm{Fe}$ & & 1.00 & $\mathbf{- 0 . 5 2}$ & $\mathbf{- 0 . 4 3}$ & -0.33 & -0.07 \\
$\mathrm{Cr}$ & & & 1.00 & $\mathbf{0 . 5 4}$ & $\mathbf{0 . 4 7}$ & 0.37 \\
$\mathrm{Ni}$ & & & & 1.00 & 0.22 & $\mathbf{0 . 4 6}$ \\
$\mathrm{Pb}$ & & & & & 1.00 & 0.22 \\
$\mathrm{Zn}$ & & & & & & 1.00 \\
\hline
\end{tabular}

Bold values are significant at $p<0.05$

Similarly, $\mathrm{Ti}$ and $\mathrm{Cr}$ are from different sources. The negative correlations among trace elements may also indicate that different geochemical conditions influence their concentrations within the stream sediments. On the other hand, the other trace elements correlate positively with each other. This may imply the same geochemical conditions influence their concentrations or they share a common lithogenic source.

\section{CONCLUSION}

The granulometric data generated in this study area demonstrates that the stream sediments are fine to medium grained, poorly-moderately well sorted, positive skewed and very platykurtic to leptokurtic indicating mixed sediments. Non-opaque heavy mineral assemblage of the stream sediment samples are dominated by zircon, rutile and tourmaline. The heavy minerals were inferred to have been derived from migmatites, pegmatites, granites and gneiss in the study area.

The geochemical data shows that the mean values of all the analysed trace elements $\mathrm{Ti}(0.73 \pm 0.74 \%)$, Fe $(0.39 \pm 0.19 \%), \mathrm{Cr}(816 \pm 639 \mathrm{ppm}), \mathrm{Ni}(258 \pm 108 \mathrm{ppm})$, $\mathrm{Pb}(48 \pm 12.37 \mathrm{ppm})$ and $\mathrm{Zn}(502 \pm 126 \mathrm{ppm})$ are higher than their respective average crustal abundance values except for Fe. Computed threshold values indicate possible mineralization containing $\mathrm{Fe}$ and $\mathrm{Ti}$. The elements have variable spatial distribution across the 
study area. The study shows that the trace elements composition of the stream sediments is majorly lithogenic. The metal contents are fairly large and points to possible IImenite and Rutile mineralization within the geological domain. This can be further confirmed by more detailed analysis mineral chemistry and spectroscopic studies; and lends credence to the assumption that mineralisation in rocks are characterized by considerable variation in the trace elements concentrations of adjoining stream sediments.

\section{REFERENCES}

Adamu, C. I. Nganje, T. N. Edet, A. E., 2015. Heavy metal contamination and health risk assessment associated with abandoned barite mines in Cross River State, southeastern Nigeria. Environmental Nanotechnology, Monitoring and Management, 3: 10-21

Basu, A., 2003. A perspective on quantitative provenanceanalysis. In: Valloni, R., Basu, A. (Eds.), Quantitative Provenance Studies in Italy, MemorieDescrittivedella Carta Geologicadell' Italia, 61: 11-22.

Basu, A. and Molinaroli, E., 1989. Provenance characteristics of detrital $\mathrm{Fe}-\mathrm{Ti}$ oxide minerals. Journal of Sedimentary Petrology. 59, 922 934.

Cannon, W.F., Woodruff, L.G. and Pimley S., 2004. Some statistical relationships between stream sediment and soil geochemistry in northwestern Wisconsin. Can stream sediment compositions be used to predict compositions of soils in glaciated terranes? Journal of Geochemical Exploration,81: 29-46.

Carver, R. E., 1971. Heavy mineral separation. In: Procedures in sedimentary petrology. Carver, R. E (Ed.), New York:Wiley. pp 427 - 452.

Cohen, D.R., Silva-Santisteban, C.M., Rutherford, N. F., Garnett, D.L. and Waldron H. M., 1999. Comparison of biogeochemical and stream sediment geochemical patterns in the north eastern region of NSW. Journal of Geochemical Exploration,66, 469-489.

Darby, D. A., 1984: Trace elements in ilmenite: a way to discriminate provenance or age in coastal sands. Geological Society of America Bulletin. 95, 1208-1218.

Darby, D.A. and Tsang, Y. W., 1987: Variation in ilmenite element composition within and among drainage basins: implications for provenance. Journal of Sedimentary Petrology,57, 831 838.

Davis C. J., 1986. Statistics and data analysis in geology ( $2^{\text {nd }}$ edition). John Wiley and Sons, Toronto.
Ekwueme B. N., 2005. Geological excursion guidebook. Bachudo Printing Press, Calabar.

Elueze A.A., and Olade M. A., 1985. Interpretation through factor analysis of stream sediment reconnaissance data for gold exploration in llesha greenstone belts, SW Nigeria. Trans. Int. Min. Metall.94, B155-B160.

Folk, R.L. and Ward, W. C., 1957. Brazos River bar, a study in the significance of grain size parameters. Journal of Sedimentary Petrology,27:3-27

Frihy O.E. and Komar P. D., 1991. Patterns of beachsand sorting and shoreline erosion on the Nile Delta. Journal of Sedimentary Petrology, 61: 544-550.

Grunsky E.C., Drew L.J., David M. and Sutphin D. M., 2009. Process recognition in multi-element soil and stream-sediment geochemical data. Applied Geochemistry, 24: 1602-1616.

Hanamgond, P. T. and Nayak, G. N., 2011. Geochemistry of Heavy Minerals of Beach Sediments at Arge West Coast of India. International Journal of Earth Sciences and Engineering. 4(2), 52-60.

Haruna I.V., Dada S.S. and Mamman Y. D., 2008. Stream Sediment Geochemical Survey of an Area around Dass, NE Nigeria. Global Journal of Geological Sciences Vol. 6 No. 2: 105-112.

Hubbert, J.F., 1962. A Zircon-Tourmaline-Rutile maturity index and the interdependence of the composition of heavy mineral assemblages with the gross composition and texture of sandstones. Journal of Sedimentary Petrology, 32: $440-450$.

Ikhane, P.R., Akintola, A.I., Bankole S.I.,Oyebolu O. O. and Ogunjana E.O., 2013. Granulometric analysis and heavy mineral studies of sandstone facies exposed near Igbile, southwestern Nigeria. International Research Journal of Geology and Mining, 3(4): 158 - 178.

JimohM.T., Bolarinwa A.T. and Kolawole T., 2015. Geochemical stream sediments reconnaissance of the schist belt around Igbo-ora, southwestern Nigeria. Journal of Geology and Mining Research, 7(7): $65-73$.

Joe, A.J., 2006.Fundamental statistics. Kraft, Ibadan.

Levinson, A. A., 1974. Introduction to Exploration Geochemistry. Applied Publishing. Wilmette, Illinois.

Mange, M.A. and Wright, D. T., 2007. Heavy mineral in use. Developments in Sedimentology, 58: 1571247. 
Oboho, U. U., Ekwere S. J., Nganje T. N. and Adamu C. I., 2007. Dispersal of heavy metals in the stream sediments of eastern Oban Massif, southeastern Nigeria. International Journal of Natural and Applied Sciences, 2(2): $81-86$.

Okon, E.E. and Essien, N.U., 2015. Depositional processes and provenance determination using grainsize analysis and heavy mineral assemblages of surficial sediment and stream sediment samples from Iwere-lle and its environs. International Journal of Scientific and Engineering Research. 6(11): 1238 - 1246.

Peterson, C. D., Komar, P. D. and Scheidegger, K. F., 1986: Distribution, geometry, and origin of heavy mineral placer deposits on Oregon beaches. Journal of Sedimentary Petrology,56: 67-77.

Pettijohn, F. J., 1975. Sedimentary Rocks, 3rd Edition, Harper and Row.

Rahaman, M. A., 1976. Review of the basement geology of southwestern Nigeria, In: Kogbe, C.A. (ed.)
Geology of Nigeria. Elizabethan Publishing Company. Lagos, 41-58.

Ranasinghe, J. A., Weisberg, S. B. Smith, R. W. Montagne, D. E. Thompson, B. Oakden, J. M. Huff, D. D. Cadien, D. B. Velarde R. G. and Ritter. K. J.,2009. Calibration andevaluation of five indicators of benthiccommunity condition in two California bay andestuary habitats. Marine Pollution Bulletin. 59: 5-13.

Selley, R. C., 1976. An introduction to Sedimentology. Academic Press Inc, (London). 408p.

Singh P., 2010. Geochemistry and provenance of stream sediments of the Ganga River and its major tributaries in the Himalayan region, India. Chemical Geology. 269: 220-236

Suresh-Ghandi, M. and Raja, M., 2014. Heavy mineral distribution and geochemical studies of coastal sediments between Besant Nagar and Marakkanam, Tamil Nadu. Indian Journal of Radiation Research and Applied Sciences. 7, 3: $256-268$. 